\title{
Leitorado-eleitorado:
}

\section{Análise da cobertura noticiosa e das preferências políticas dos leitores-eleitores de um jornal de prestígio, um jornal popular e um jornal ultrapopular do Rio de Janeiro ${ }^{1}$}

\section{Por Viktor Chagas}

\section{Introdução}

Resultado de uma disputa eleitoral acirrada ${ }^{2}$, fruto dos mesmos velhos conflitos entre as oligarquias dominantes ${ }^{3}$, legado do discurso do "medo" ou do "ódio", consequência concreta do vácuo após o fim do mandato de políticos que concentraram poder e carisma ${ }^{5}$, efeito do recrudescimento do neopopulismo conservador ${ }^{6}$. São muitas as causas evocadas por inúmeros cientistas políticos - entre leigos e acadêmicos -, que procuram dar conta da percepção de uma crescente polarização no cenário político brasileiro pós-2014. As eleições de 2014 são consideradas, em grande parte dessas análises, como o clímax para esse comportamento, enquanto as Jornadas de Junho de 2013 geralmente aparecem lembradas como ponto de inflexão, já que a partir daquele episódio os índices de popularidade de Dilma Rousseff despencaram abruptamente. Os mapas de votação eram claros em apontar uma linha divisória que cindia norte e sul do país de acordo com a preferência do eleitorado. Esta linha, contudo, não mais do que uma

\footnotetext{
1 Uma versão preliminar deste texto foi apresentada no Encontro da ABCP, em 2016, em Belo Horizonte, na AT de Comunicação Política. A presente versão conta com adições e revisões em função dos comentários recebidos de colegas do grupo de trabalho, a quem agradecemos pela revisão. Pesquisa apoiada com recursos do edital nำ 14 Universal/CNPq/2013 e PDJ/2018 nº 150035/20187.

2 Cf. <http://bit.ly/cartacapital2016>. Acesso: 19/04/2018.

${ }^{3}$ Cf. <http://bit.ly/ultimosegundoig2016>. Acesso: 19/04/2018.

${ }^{4}$ Cf. <http://bit.ly/folha2016>. Acesso: 19/04/2018.

${ }^{5}$ Cf. <http://glo.bo/2a3NbAG>. Acesso: 19/04/2018.

${ }^{6}$ Cf.<http://glo.bo/29VsJTd>. Acesso: 19/04/2018.
} 


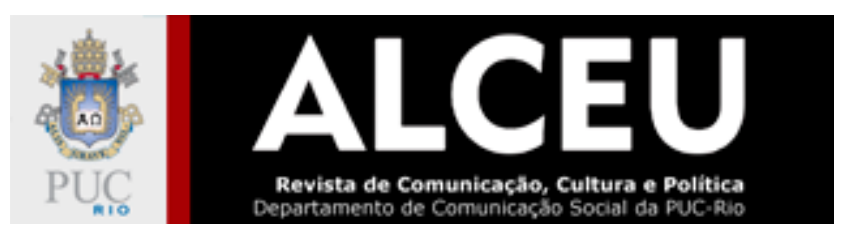

linha maginot, é apenas um sintoma de um panorama bastante mais abrangente, que relaciona a escolha racional à experiência de letramento político das massas. Por essa leitura, a polarização é, antes de mais nada, um recurso empreendido para explicar as possibilidades reais de alternância de poder no cenário atual, isto é, uma simplificação grosseira de um determinado contexto semântico. A imagem da polarização, calcada em estereótipos, não permite a apreensão das complexas relações de força presentes no pluripartidarismo brasileiro, mas é útil para explicar ao cidadão comum, parcialmente alienado da política, as diferenças ideológicas mais marcantes entre os projetos de governo que disputam o poder.

Diferentes autores (LATTMAN-WELTMAN, 2006; MIGUEL, 2003) têm buscado explorar a interface entre os estudos de mídia e a política, em especial chamando a atenção para a influência que os meios de comunicação são capazes de exercer sobre não apenas a tomada de decisão individual, mas todo o processo de formação da opinião pública. Este artigo não tem a intenção de repisar esse terreno; nem de estabelecer, ao modo do que fazem os estudiosos da teoria dos efeitos, relação de causa ou efeito entre a cobertura midiática e os humores do público. Nosso principal interesse é meramente identificar paralelos entre o consumo das mídias e leituras do cenário político (ou, mais especificamente, preferências eleitorais). Assim, não buscamos avaliar como repercute ou se origina na mídia esse ambiente polarizado, mas tão somente percebê-lo como decorrente de um processo anterior de partidarização e tabloidização da informação política nos meios tradicionais.

As principais questões que procuramos levantar a partir deste trabalho podem ser resumidas nas duas perguntas que se seguem:

(Q1) A que tipo de informação política estamos sujeitos através da mídia?

(Q2) De que modo tais informações nos são apresentadas pelos diferentes veículos de mídia? Isto é, como vetores econômicos, como a propriedade dos meios e o perfil de consumo do público, podem influenciar na produção de enquadramentos midiáticos sobre a política?

Este trabalho procura desdobrar e aprofundar análises tecidas anteriormente a partir da comparação entre a cobertura noticiosa durante o período eleitoral, propondo uma discussão sobre o papel dos conglomerados midiáticos na construção ou reprodução da visão política do eleitorado. A presente etapa de investigação se insere em uma agenda interinstitucional de pesquisa, que tem procurado discutir a reconfiguração político-econômica da mídia brasileira, com ênfase particular 
na performance dos jornais impressos. Não se trata de desconsiderar o ambiente de convergência midiática a que o indivíduo contemporâneo está exposto no acesso à informação política, nem muito menos de sobrevalorizar o impacto da mídia impressa em relação aos demais meios, mas de tomar os jornais como um recorte de análise, face ao seu histórico posicionamento como guardiões dos valores mais caros ao ethos jornalístico, quais sejam, independência e liberdade de expressão.

Os jornais têm enfrentado uma intensa crise de vendas, que, de certa maneira, está associada a uma crise segunda, de credibilidade e confiança. Temos argumentado, porém, que essas dificuldades se apresentam de modo desigual na paisagem econômica dos meios impressos, afligindo com maior prejuízo os títulos mais tradicionais, enquanto os jornais populares têm podido encontrar cenário favorável para sua expansão. Para enfrentar esses desafios, jornais de prestígio têm optado por duas principais estratégias: (E1) construir modelos econômicos baseados em um portfólio de produtos diversificado, que lhes permita alcançar públicos variados através de títulos que atuam no mercado de forma complementar, como tabloides e quality papers (CHAGAS, 2014); e (E2) lançar mão de um discurso mais parcial e tendencioso, com vistas a agradar uma base leitora fiel, formada por assinantes que já se identificam com a linha editorial daquele jornal (LATTMANWELTMAN \& CHAGAS, 2017). Os jornais populares, em contrapartida, não podem assumir com clareza suas posições editoriais, já que dependem do resultado direto da vendagem em banca, cuja margem de consumo é sempre instável. Os reflexos políticos desse cenário devem ser considerados.

No presente artigo, dividimos nossa discussão teórico-metodológica em dois segmentos distintos, procurando conjugá-los ao longo dos diferentes capítulos em que organizamos nossa discussão. Em primeiro lugar, para avaliarmos os resultados de (E1), procuramos recuperar o debate sobre os efeitos da concorrência entre jornais tradicionais e jornais populares, no que, na literatura, é reconhecido a partir dos estudos sobre o processo de tabloidização dos meios. Nosso interesse é reconhecer as diferenças e similaridades entre quality papers e tabloides, o que proporcionará um duplo ganho a esta pesquisa: de um lado, teremos maior clareza sobre o que caracteriza o gênero tabloide quando o conceito é aplicado à realidade brasileira (Q2); e, de outro, poderemos perceber qual a qualidade da informação política veiculada por estes meios (Q1). Além disso, para avançarmos sobre o debate relacionado à "re-partidarização" da mídia, sustentado pelos resultados de (E2), tratamos de aprofundar a investigação sobre a relação entre o conteúdo 
produzido pelos meios noticiosos impressos e o perfil político de seus consumidores (Q2). Para tanto, sem nos preocuparmos em estabelecer causalidade, partimos do reconhecimento de diferentes tratamentos e enquadramentos dos meios noticiosos a um mesmo contexto, o das Eleições 2014. Entender como operam esses enquadramentos é, em última instância, fundamental também para percebermos a que tipo de informação política somos expostos (Q1). Dividimos, portanto, este artigo em cinco momentos distintos, além desta introdução. No primeiro, revisitamos o debate teórico sobre a tabloidização e procuramos apontar ganhos e limitações desse modelo. No segundo, apresentamos uma breve contextualização do conceito de enquadramento, apostando em uma possível interface com a análise comparativa entre tabloides e jornais de prestígio. A partir daí, apresentamos um duplo aporte empírico. Utilizando, como ponto de partida, o modelo de análise de Sparks (2000) sobre a tabloidização, buscamos desenvolver uma matriz que avalia a cobertura noticiosa de três diferentes jornais fluminenses, a saber: O Globo (um típico quality paper), Extra (um jornal de porte intermediário), e Meia Hora (um jornal ultrapopular). Depois, estabelecendo relações entre a preferências políticas dos leitores de jornais no Rio de Janeiro e seus hábitos de leitura, avaliamos a cobertura política desses jornais conjugando à análise de conteúdos previamente desenvolvida uma análise de enquadramentos inspirada em Entman (2004; 1993). Por fim, apresentamos os resultados e conclusões desta etapa de investigação.

\section{Letramento e tabloidização: jornalismo e cultura popular}

A ideia de que atravessamos uma fase de extrema polarização política, entre PT e PSDB (ou entre correntes petistas e antipetistas pós-2016), no caso brasileiro, desconsidera o papel não apenas de uma eventual terceira via, mas de forças que desequilibram o jogo eleitoral mesmo razoavelmente de fora da disputa, como tem sido o papel do MDB. A que serve então essa visão? O debate travado em fins da década de 1990 entre pesquisadores dedicados a estudar o processo da tabloidização se ocupou justamente de entender em que medida esse tipo de recurso a visões estereotipadas e simplificadas da realidade é ou não útil ao jornalismo. $E$ as visões sobre o fenômeno não eram menos polarizadas.

De lados opostos, figuravam uma corrente de autores que argumentava que a qualidade da informação política vinha se perdendo paulatinamente, em decorrência da competição entre o 
jornalismo tradicional e o jornalismo tabloide, e outra que enxergava neste último justamente horizonte para que as classes populares se afirmassem. Como lembra Peck (2000, p. 230),

[...] esta polaridade caracteriza o debate sobre a tabloidização em geral - um debate que tende a coalescer ao redor de uma série de oposições binárias: informação/entretenimento, educação/diversão, público/privado, razão/ emoção, obrigação/prazer, cidadão/consumidor. Se os críticos da tabloidização tipicamente privilegiam o primeiro conjunto de termos e seus advogados abraçam o segundo, ambos dizem muito a respeito do que eles tratam como a noção de 'processo democrático'.

Peck (2000) ainda sustenta que a ideologia contida na valorização do letramento enquanto experiência de leitura "séria" é herdeira do contexto de emergência de novos públicos leitores a partir da ascensão da burguesia e da esfera pública literária, que continuaria servindo de paradigma para modelar certa compreensão de cidadania. Autores alinhados a essa perspectiva, como Sparks (2000), Esser (1999), e Klein (2000), costumam criticar o sobrepeso à informação visual, em detrimento do texto, e a informalidade da notícia, em oposição à informação factual e concernente à vida pública. O tabloide, para esses autores, representa o "colapso" da política no pessoal (PECK, 2000, p. 246).

Em contraste direto com essa concepção, nomes como Bird (2000; 2010), Gans (2010), e Glynn (2000), defendem o jornalismo tabloide, sustentando que o tom coloquial equilibra as posições assumidas por produtores e consumidores das notícias e confere um potencial "antiautoritário" e "progressista" (PECK, 2000), que subleva a perpetuação das distinções binárias entre alta e baixa cultura, típica da prática disciplinar dos meios tradicionais. Curiosamente, esses pesquisadores, tidos como teóricos populistas, dada a influência das ideias de Fiske (2011) em seu pensamento, acusam seus pares de avocar um visão estreita que impede as classes populares de exercerem suas escolhas culturais. Seguindo esse raciocínio, a dita imprensa tradicional operaria no sentido de consolidar visões estabelecidas, em consonância com o paradigma de informação política de qualidade próprio dos grupos no poder. Por essa mesma razão, argumenta-se que a "tabloidização" em realidade seria um conceito problemático e arbitrário, pois estaria investido de uma "alegada deterioração do conteúdo informacional e intelectual" (GANS, 2010, p. 17). De acordo com Herbert Gans (2010), a "tabloidização" seria melhor compreendida se substituída pela expressão "popularização", pois esta última é termo apreciado mesmo entre os detratores dos tabloides. Popularizar a informação política ganha sentido completamente distinto, diz. E, se 


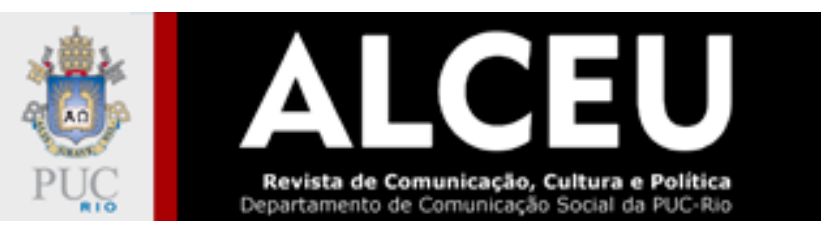

entendemos que a sociedade deve desconstruir paradigmas artísticos e estéticos, quando se diz respeito à informação, a substância da notícia - que é sempre baseada em evidência empírica (empirical accuracy) - é independente de sua apresentação, de modo que, se entendemos que as necessidades do cidadão sobre "o que ele deve saber" não variam de acordo com sua posição na escala social, nós ainda assim não sabemos muito sobre o que ele consome da notícia e nem como as notícias chegam a ele (GANS, 2010, p. 21-22).

A popularização da notícia, nesse caso, ganha um contorno positivo, por atrair a atenção do indivíduo para um dado assunto - à moda do que faz a popularização da ciência. Contudo, ela se mantém distante do ideal normativo do debate público, fundamentando-se primordialmente no olhar sobre o acesso à informação pelo indivíduo comum.

A notícia, lembra Fiske (1992), para se tornar popular, deve provocar um circuito de conversação. Por isso também, sua apreensão é facilitada tanto mais simplificados forem os seus termos. Dessa forma, é interessante atentarmos para o fato de que a estratégia da imprensa de prestígio para facilitar o acesso à notícia é exatamente idêntica à da imprensa popular, em apostando mormente em escândalos e rumores para apelar ao interesse do público. Nesse sentido, concordamos com Bird (2010, p. 44), para quem a tabloidização sempre foi parte essencial da notícia, "a despeito dos críticos que a veem como anátema do jornalismo real". Mesmo assim, a ressalva feita por Sparks (2000, p. 37), conforme evidenciamos, permanece atual: a popularização pode ser um processo importante, mas ela não é equivalente ao impetrado pela imprensa popular, já que o leitor dos tabloides não recebe informação em profundidade da mesma maneira que o leitor de um quality paper. Por isso mesmo é que Sparks (2000) se ocupa de desenvolver um modelo teórico para avaliar a escala de tabloidização dos veículos midiáticos, em que dispõe em dois eixos transversais os conteúdos noticiados. Em sua categorização (fig. I), os conteúdos podem variar de uma concentração em escândalos, esportes e entretenimento a uma concentração em política, economia e sociedade, no eixo $x$; e de uma concentração em temas concernentes à vida privada a uma concentração em temas concernentes à vida pública, no eixo $y$. Segundo Sparks (2000), os eixos definiriam um espectro linear diagonalmente orientado do quadrante inferior direito (imprensa tabloide) ao quadrante superior esquerdo (imprensa "séria"), mas, na prática, as variações não obedecem a essa disposição em linha reta, o que só reforça o fato de que, mais do que meramente um processo (ESSER, 1999), a tabloidização também deve ser compreendida como expediente dos jornais em determinadas coberturas. 


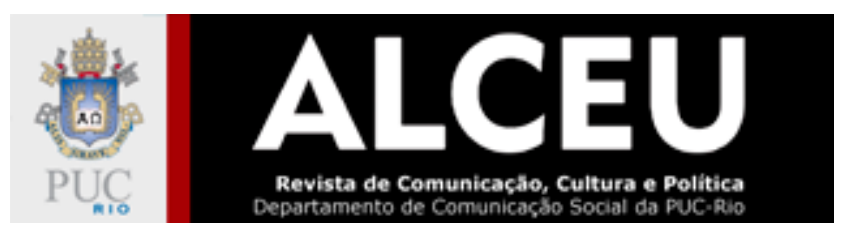

No que se segue, pretendemos testar empiricamente o modelo de Sparks, analisando a cobertura noticiosa de diferentes jornais. Dadas as limitações do modelo, trabalharemos de forma associada com uma análise de enquadramentos. Nossa intenção, entre outros aspectos, é desenvolver um ferramental analítico adequado à realidade brasileira, que nos permita distinguir com maior propriedade um jornal tabloide de um quality paper, e, consequentemente, apreender como a informação política é tratada por cada um desses meios. Antes disso, passemos a uma contextualização sobre os usos do conceito de enquadramento.

\section{IMAGEM I. Modelo de Sparks}

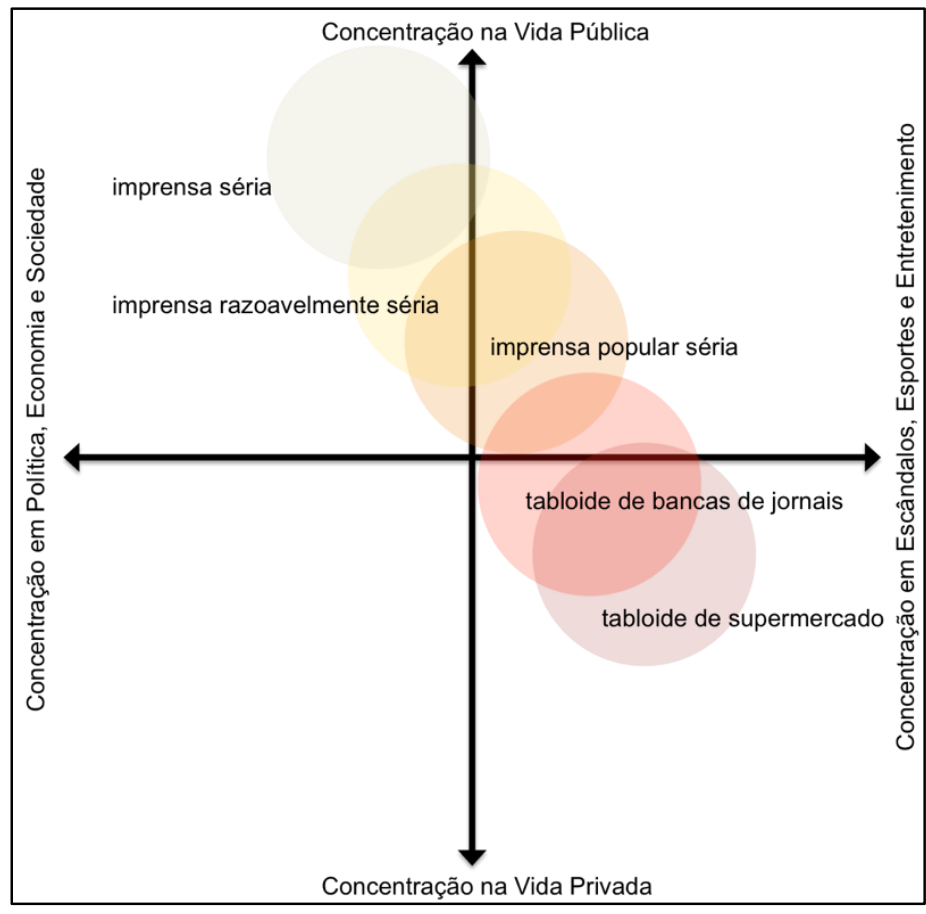

Fonte: Elaboração própria, com base em SPARKS, 2000.

\section{Enquadramento e tabloidização: jornalismo e opinião pública}

A imagem da polarização do processo eleitoral caminha em paralelo com a percepção de que essa mesma polarização tem contribuído para uma crescente radicalização do eleitorado, cujo expoente maior são as trocas de farpas e agressividade no ambiente das mídias sociais, noticiadas pelos jornais com grande preocupação. Mas, embora essa imagem dê conta de traduzir a rivalidade entre os dois principais projetos políticos que se apresentaram ao país nos últimos anos, ela é 
também uma simplificação grosseira da realidade. E, como tal, é um artifício da imprensa para alcançar o público.

Não se trata aqui de recobrarmos todo o debate teórico sobre o conceito de enquadramento, revisão que foi já muito bem empreendida por diferentes autores (MENDONÇA \& SIMÕES, 2012; PORTO, 2002). Tampouco tentaremos conciliar suas diferentes apropriações, como modelo de análise de situações interativas ou de conteúdo discursivo. Os enquadramentos que abordaremos no decorrer deste texto encaixam-se nesta última categoria, pois nosso interesse será compreender como as Eleições 2014 foram tratadas por títulos de diferentes perfis econômicos. Entretanto, embora a noção de enquadramento, conforme trabalhada por Entman (2004, p. 13; 52) - como uma "representação seletiva" de "aspectos da realidade" ressaltados em um "texto comunicativo" nos auxilie na compreensão de nossos objetivos, os enquadramentos que aqui discutimos não se referem a uma controvérsia entre possibilidades de representação de um tema em um mesmo veículo de comunicação, como sugere o próprio autor (ENTMAN, 1993), mas a uma disputa de sentidos externa, perceptível apenas ante uma análise comparativa, entre diferentes veículos.

Matthes (2009) acrescenta ainda que a conceituação de tipos de enquadramentos é muitas vezes imprecisa empiricamente. Operacionalizar esse conceito exige uma definição do pesquisador sobre o que é considerado no tratamento empírico, já que os enquadramentos podem se referir a unidades de discurso (visual ou somente textual) ou proposições, quadros construídos genericamente (corrida-de-cavalos, frames temáticos etc.) ou orientados a um tema em particular (polarização, desejo de mudança etc.). A análise pode também ser dedutiva ou indutiva, qualitativa ou quantitativa (MATTHES, 2009, p. 350-352). Em todos esses casos, como indica Entman (2004), os enquadramentos podem ser substantivos ou procedimentais. Os enquadramentos substantivos apresentam funções que vão da definição do problema e dos agentes causadores à avaliação geral e recomendação de uma solução. São representações seletivas da realidade construídas a partir de um esquema, isto é, um processo interpretativo que entrelaça atores e instituições em uma rede de conhecimento (knowledge network). Já os enquadramentos procedimentais "têm funções e foco mais restritos" (p. 6) e se concentram sobre a legitimidade dos atores envolvidos, procurando avaliar a posição estratégica que ocupam. Trata-se de uma leitura dos enquadramentos como afeitos ao jogo político. Por isso, autores como lyengar (1994) aproximarão o conceito da ideia de "formato da notícia" (news format) e definirão papéis binários aos enquadramentos, classificando-os a partir de variáveis, e distinguindo-os entre enquadramentos temáticos (thematic) ou episódicos 
(episodic). Os enquadramentos temáticos dispõem dos eventos e das questões políticas de modo generalista, apresentando um panorama diversificado sobre um determinado aspecto da realidade. Em contraposição, os enquadramentos episódicos enfatizam circunstâncias particulares, casos concretos e situações de disputas de sentido ou performance dos atores retratados. Cappella \& Jamieson (1997) aludem a categorias semelhantes para desenvolver seu método de análise. Os autores dividem os enquadramentos em questões (issue) e estratégias (strategy), apontando que, muito embora "construir, compreender e provar a existência de enquadramentos noticiosos não seja, de modo algum, equivalente a determinar seus efeitos sobre aquele que consome a notícia" (p. 48), os enquadramentos não são apenas modos de representar o conteúdo noticioso mas modos de processar a notícia. Assim, chamam atenção para a relação entre a análise de enquadramentos e a teoria dos efeitos. Na discussão que propõem, o uso intensivo de um enquadramento de estratégia sobre a cobertura política poderia levar a um desinteresse e descrença pela política.

$\mathrm{Na}$ discussão que lançamos, foram empregados dois diferentes métodos para operacionalizar nossa análise de enquadramentos, trabalhando simultaneamente com a definição de esquema e enquadramento substantivo de Entman (2004) e a perspectiva de lyengar (1994) sobre enquadramentos procedimentais como variáveis ou formatos de notícia. Desse modo, esperamos conseguir identificar as nuances que caracterizariam um eventual processo de tabloidização (CHAGAS, 2016) e re-partidarização (LATTMAN-WELTMAN \& CHAGAS, 2017) da imprensa brasileira. A análise de enquadramentos, porém, foi precedida por uma análise de conteúdos, que procurou identificar como a cobertura noticiosa dos jornais investigados se dividiu em relação à abordagem temática e de interesse público, conforme os parâmetros estabelecidos pelo modelo de Sparks.

\section{Análise da cobertura eleitoral de jornais fluminenses}

Entre maio e outubro de 2014, uma série de seis pesquisas de opinião encomendadas pelo diretório do então PMDB do Rio de Janeiro ao Instituto GPP, procurou indicar as preferências eleitorais dos cidadãos fluminenses para o voto para deputado, senador, governador e presidente da República. Intercalando mensalmente resultados de sondagens para eleições proporcionais com eleições majoritárias, os relatórios ficam parcialmente comprometidos a partir do acidente que 
vitimou o então candidato Eduardo Campos em 13 de agosto de 2014, já que a sondagem presidencial divulgada na primeira semana de agosto incluía o candidato e foi o último relatório apresentado antes do primeiro turno pelo instituto. Desconsiderados esses inconvenientes, 0 relatório de outubro de 2014 traz a sondagem de opinião referente ao segundo turno para as eleições para presidente, disputado entre os candidatos Dilma Rousseff e Aécio Neves. A pesquisa apresentada pelo Instituto GPP, às vésperas do segundo turno, tem uma peculiaridade interessante, que é apresentar cruzamentos de dados entre as intenções de voto dos eleitores e suas preferências de leitura de jornal diário.

Nós utilizamos estes dados como referência para construir o argumento de que os hábitos de consumo da informação política têm se alterado, o que, evidentemente, guarda relações com um processo que ocorre em simultâneo ao de reconfiguração do ecossistema dos meios de comunicação em geral. A pesquisa (tabela I) indicava que, dentre os principais jornais fluminenses, O Globo era o único com tendência favorável, entre seus leitores, a apoiar a candidatura de Aécio Neves. Eram 55,8\% de leitores que declaravam voto no candidato do PSDB contra $31,2 \%$ de leitores que declaravam voto em Dilma Rousseff. A diferença era revertida em leitores do Extra (44,2\% a favor de Dilma; 40,9\%, de Aécio), de O Dia (43,4\% para Dilma, e 41\% para Aécio) e de Meia Hora (56,6\% para Dilma contra 37,7\% para Aécio), além dos respondentes que afirmavam não ler jornal (entre os quais 45,2\% indicavam voto em Dilma e 38,4\% em Aécio).

Tabela I. Intenção de voto por hábito de consumo de jornal impresso

\begin{tabular}{|c|c|c|c|c|}
\hline & \multicolumn{2}{|c|}{ Dilma Rousseff } & \multicolumn{2}{c|}{ Aécio Neves } \\
\hline & Total & Votos válidos $^{*}$ & Total & Votos válidos $^{*}$ \\
\hline O Globo & $31,2 \%$ & $35,9 \%$ & $55,8 \%$ & $64,1 \%$ \\
\hline Extra & $44,2 \%$ & $51,9 \%$ & $40,9 \%$ & $48,1 \%$ \\
\hline O Dia & $43,4 \%$ & $51,4 \%$ & $41 \%$ & $48,6 \%$ \\
\hline Meia Hora & $56,6 \%$ & $60,0 \%$ & $37,7 \%$ & $40,0 \%$ \\
\hline Não lê jornal & $45,2 \%$ & $54,1 \%$ & $38,4 \%$ & $45,9 \%$ \\
\hline Resultado global & $43,9 \%$ & $51,1 \%$ & $42 \%$ & $48,9 \%$ \\
\hline
\end{tabular}

Fonte: Instituto GPP e (*) Elaboração própria.

Os dados chamam a atenção para o fato de que, entre os leitores de jornais no Estado do Rio de Janeiro, a candidata petista possui maior apoio justamente naqueles que se identificam com jornais do estrato popular ou ultrapopular. Tais títulos são prioritariamente comercializados mediante venda avulsa em bancas de jornais, e, portanto, não apresentam aquilo que Toussaint (1979) e Chagas (2013) caracterizam como uma base fiel de leitores, já que seu desempenho no 
mercado está sujeito às flutuações cotidianas, o que os distingue de títulos marcadamente sustentados por sua base de assinantes, como O Globo.

Tomando como ponto de partida esses resultados, desenvolvemos um modelo de análise que procurou avaliar o conteúdo desses jornais de acordo com as características que distinguem um quality paper de um tabloide, segundo Sparks (2000). Dessa forma, esperamos responder à questão que procura determinar a que tipo de informação cada público está sujeito conforme suas preferências de leitura entre os jornais diários.

Para empreender essa análise, recuperamos as primeiras páginas e capas de três dos cinco jornais de maior circulação no Rio de Janeiro, a saber: O Globo, Extra e Meia Hora. A razão por termos excluído Expresso e O Dia de nosso corpus diz respeito a duas considerações. Em primeiro lugar, estes jornais apresentam sobreposições em relação ao perfil econômico pretendido pelos veículos já presentes na amostra - O Dia, por exemplo, é concorrente do Extra no estrato BC; e Expresso é concorrente de Meia Hora no estrato CD. Ademais, esses dois jornais não possuem um sistema que permita recuperar suas capas em pesquisa pelo histórico das edições - Expresso sequer possui um site oficial ${ }^{7}$.

Assim, foram analisadas mais de duas mil manchetes e chamadas de primeira página dos três jornais que compuseram nossa amostra, no período entre julho e outubro de 2014, correspondente ao período de propaganda eleitoral, conforme definido pelo TSE. São cerca de 330 capas de jornais ${ }^{8}$, em que se buscou identificar, para cada notícia ou chamada de capa, o grau de cobertura política no noticiário, observando-se uma variação entre notícias relacionadas a $(A)$ esportes e entretenimento, (B) economia e sociedade ou (C) política, e um tratamento que enfatizava questões concernentes à (a) vida privada e atores individuais ou à (b) vida pública e atores institucionais. Notícias classificadas em $(\mathrm{A})$ relacionam-se geralmente à cobertura esportiva ou sobre celebridades. Por sua vez, (B) engloba conteúdos relacionados à vida e sociedade, à cobertura econômica, sobre comportamento, ciência, saúde e segurança pública. Finalmente, (C) trata de conteúdos relacionados à política em sentido estrito, incluindo, é claro, as Eleições 2014. No eixo vertical, (a) concentra notícias com foco em coberturas locais, eventos de curta duração ou

\footnotetext{
${ }^{7}$ No caso de $O$ Globo e Extra, as primeiras páginas foram recuperadas através dos sites dos jornais. Já Meia Hora possui uma página no Facebook que publica diariamente sua capa aos seguidores.

8 Foram coletadas 113 capas de Meia Hora, 113 primeiras páginas de Extra e 112 primeiras páginas de O Globo. Por razões alheias à nossa vontade, não puderam ser recuperadas uma capa do primeiro jornal, uma do segundo e duas do terceiro. As lacunas, no entanto, não comprometem os resultados da pesquisa.
} 
com ênfase em atores individuais, enquanto (b), ao contrário, concentra notícias com foco em atores institucionais, eventos de longa duração e de impacto nacional ou internacional ${ }^{9}$. A análise resultou nos dados a seguir.

Tabela II. Análise de conteúdo (1)

\begin{tabular}{|c|c|c|c|c|c|}
\hline & $\begin{array}{c}\text { Esportes e } \\
\text { entretenimento } \\
(\mathrm{A})\end{array}$ & $\begin{array}{c}\text { Economia e } \\
\text { sociedade } \\
(\mathrm{B})\end{array}$ & Política (C) & Outros & Total \\
\hline $\begin{array}{c}\text { O Globo } \\
(\mathrm{N}=1080)\end{array}$ & $17,9 \%$ & $33,9 \%$ & $44,5 \%$ & $3,7 \%$ & $100,0 \%$ \\
\hline $\begin{array}{c}\text { Extra } \\
(\mathrm{N}=1036)\end{array}$ & $40,4 \%$ & $39,4 \%$ & $15,6 \%$ & $4,6 \%$ & $100,0 \%$ \\
\hline $\begin{array}{c}\text { Meia Hora } \\
(\mathrm{N}=457)\end{array}$ & $58,9 \%$ & $32,2 \%$ & $3,5 \%$ & $5,5 \%$ & $100,0 \%$ \\
\hline $\begin{array}{c}\text { Total } \\
(\mathrm{N}=2573)\end{array}$ & $34,2 \%$ & $35,8 \%$ & $25,6 \%$ & $4,4 \%$ & $100, \%$ \\
\hline
\end{tabular}

Fonte: Elaboração própria.

Tabela III. Análise de conteúdo (2)

\begin{tabular}{|c|c|c|c|c|}
\hline & Vida privada (a) & Vida pública (b) & Outros & Total \\
\hline $\begin{array}{c}\text { O Globo } \\
(\mathrm{N}=1080)\end{array}$ & $48,8 \%$ & $41,7 \%$ & $9,5 \%$ & $100,0 \%$ \\
\hline $\begin{array}{c}\text { Extra } \\
(\mathrm{N}=1036)\end{array}$ & $58,3 \%$ & $31,5 \%$ & $10,1 \%$ & $100,0 \%$ \\
\hline $\begin{array}{c}\text { Meia Hora } \\
(\mathrm{N}=457)\end{array}$ & $81,6 \%$ & $11,2 \%$ & $7,2 \%$ & $100,0 \%$ \\
\hline Total $(\mathrm{N}=2573)$ & $58,5 \%$ & $32,1 \%$ & $9,4 \%$ & $100,0 \%$ \\
\hline
\end{tabular}

Fonte: Elaboração própria.

Com base nestes primeiros resultados, esboçamos, à moda de Klein (2000), algumas categorias para avaliarmos cada estrato apresentado. Assim, definimos, a partir das co-ocorrências nas tabelas anteriores, as categorias: sexo, celebridades e futebol (Aa), cultura e comportamento $(\mathrm{Ab})$, crime, terrorismo e faits divers $(\mathrm{Ba})$, grupos de interesse e accountability $(\mathrm{Bb})$, corrida $e$ agenda eleitoral $(\mathrm{Ca})$ e governança e políticas públicas $(\mathrm{Cb})$. O passo seguinte foi relacionar de volta essas categorias com o perfil dos leitores dos jornais analisados e suas preferências políticas, estimulando a comparação entre quality paper e tabloide, e quality paper e título intermediário.

\footnotetext{
${ }^{9} \mathrm{~A}$ análise procedimental procurou levar em consideração o modo como os temas eram apresentados. Se o texto indicava que a 'PM empreendeu operação em favela na Zona Sul do Rio', atribuía-se a ação a um ator institucional. Ao invés disso, se a manchete dizia que 'Orelha, o Chefão do Pó, vai fazer cera na cadeira', atribuía-se a ação a um ator individual.
} 


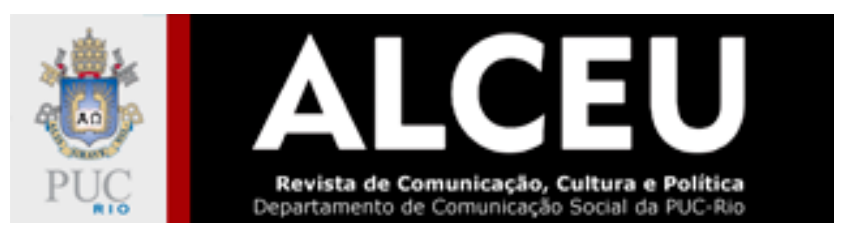

Os resultados demonstram que a cobertura dos jornais populares (Extra e Meia Hora) se concentra em Aa. Extra ainda obtém resultado equilibrado em $\mathrm{Bb}$ e $\mathrm{Ba}$, dada a incidência da cobertura temática a respeito de questões concernentes ao trabalhador, como orientações sobre a previdência, de imposto de renda e economia doméstica. Meia Hora foge do espectro esportivo apenas nos casos de narrativas policialescas e notícias de crimes. Já $O$ Globo concentra sua cobertura em $\mathrm{Ca}$ e $\mathrm{Bb}$, com peso no debate econômico e na corrida eleitoral.

Se isolarmos apenas os conteúdos referentes às Eleições $2014^{10}$, teremos que $O$ Globo publicou 352 conteúdos; o Extra, 132; e Meia Hora, apenas 15. Como era de se esperar, a cobertura de um jornal tabloide sobre política é irrisória. Entretanto, salta aos olhos a proporção entre os conteúdos que versam sobre política no sentido estrito e os conteúdos exclusivamente relacionados às eleições. Nesse caso, os números se invertem, e Meia Hora passa a ter 93,8\% de seus conteúdos de política tratando das eleições; enquanto Extra tem 82,0\%; e O Globo, 73,4\%. Em relação ao total dos conteúdos publicados no período eleitoral, 32,6\% dos títulos e chamadas de primeira página de $O$ Globo foram dedicados às Eleições 2014, ao passo que o Extra fica na faixa de $12,7 \%$, e Meia Hora, de 3,3\%.

IMAGEM II. Análise de co-ocorrências

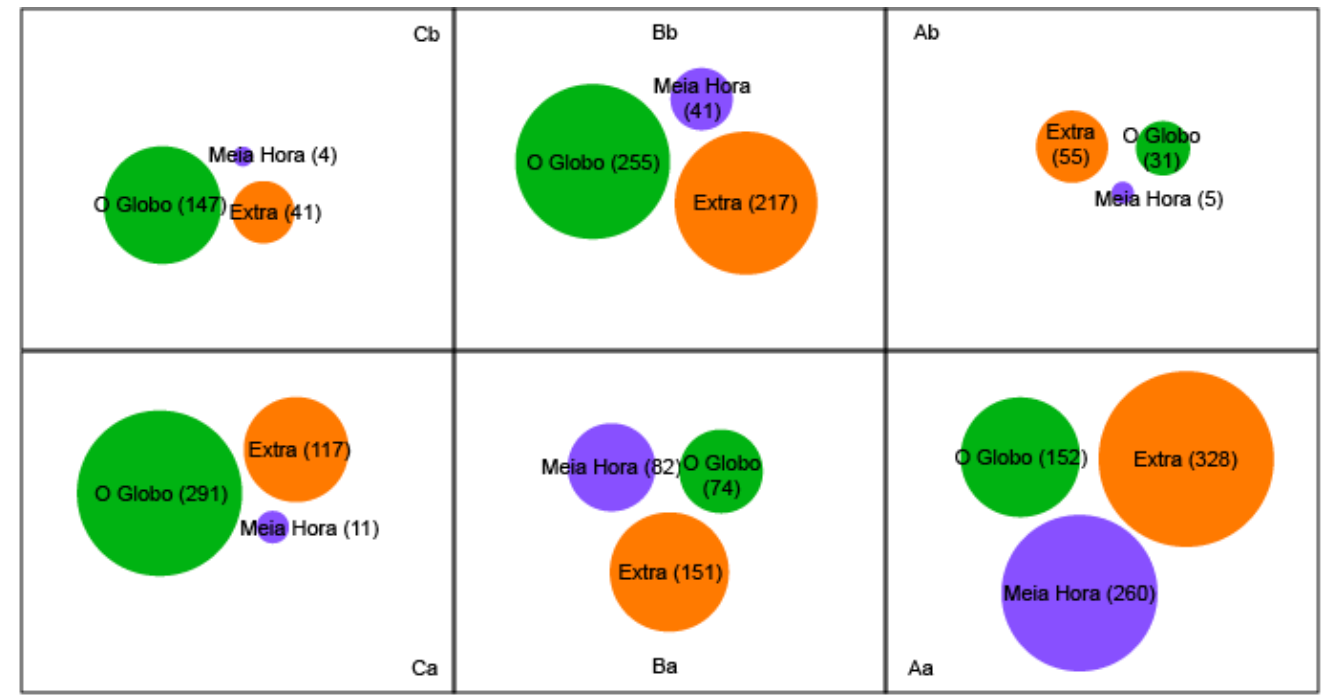

Fonte: Elaboração própria.

\footnotetext{
${ }^{10}$ Ressalte-se que os conteúdos relacionados às Eleições 2014 levam em consideração também a cobertura eleitoral nos estados.
} 


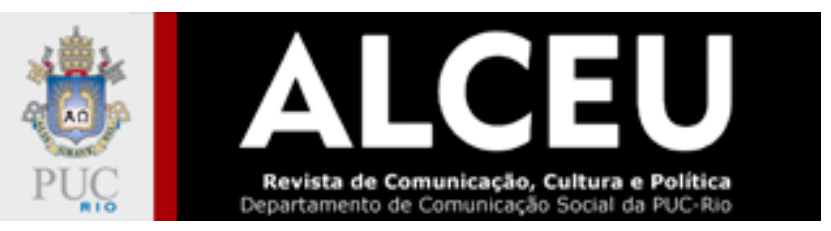

$\mathrm{Na}$ correlação entre os dados apresentados nas tabelas I, II e III (fig. III), percebemos que os eleitores de Dilma leitores dos jornais populares têm considerável menos acesso a notícias de política nos jornais que leem. Esses eleitores têm possivelmente acesso à informação política através de outras fontes, com maior ênfase aos processos de conversação. Os leitores de O Globo, por outro lado, têm maior acesso à informação política, mas a ênfase em Ca (ao invés de $\mathrm{Cb}$ ) nos permite traçar uma hipótese de que os enquadramentos a que esses sujeitos estão expostos favoreça uma percepção desacreditada da política, a partir de visão cínica e estratégica (cf. CAPELLA \& JAMIESON, 1997). Guiando-nos a partir desta série de indagações, empreendemos uma análise de enquadramentos sobre esses mesmos materiais.

\section{Relações entre leitorado e eleitorado: análise de enquadramentos de três jornais fluminenses durante as eleições}

A análise de enquadramentos sobre a cobertura noticiosa dos jornais fluminenses selecionados na amostra seguiu duas metodologias distintas. Baseando-nos em Entman (2004), procuramos avaliar funções dos enquadramentos e codificar conteúdos com base em categorias substantivas orientadas a um tema particular. Em seguida, como no modelo de lyengar (1994), distinguimos as abordagens em enquadramentos temáticos e episódicos. Para esta etapa, isolamos apenas conteúdos relacionados à cobertura política $(C)$, e dentre estes os que diziam respeito às Eleições 2014, perfazendo um total de 499 títulos e chamadas de capa, sendo 352 conteúdos de O Globo, 132 conteúdos do Extra, e 15 do Meia Hora.

O primeiro passo para a definição dos enquadramentos foi o reconhecimento dos esquemas interpretativos apresentados por cada jornal. Nós desenvolvemos esses esquemas recolhendo toda e qualquer menção a atores individuais ou institucionais nos títulos das matérias, sem atribuir tom ou valência aos laços. Ou seja, se a manchete de O Globo era "Marina ataca Aécio, que já aposta no confronto com Dilma", eram indicados no esquema três nós (Marina, Aécio e Dilma), o primeiro ligado ao segundo, e o segundo ao terceiro, sem juízo de valor sobre as ações (ataque, confronto). Também não identificamos reincidências, isto é, se Aécio apareceria ligado a Dilma em mais de uma ocasião. Os resultados são apresentados abaixo (fig. IV), donde se depreende que o 


\section{ALCEU

esquema apresentado em $O$ Globo é bastante mais complexo e tem a presença de um número consideravelmente maior de atores que os dos jornais populares.

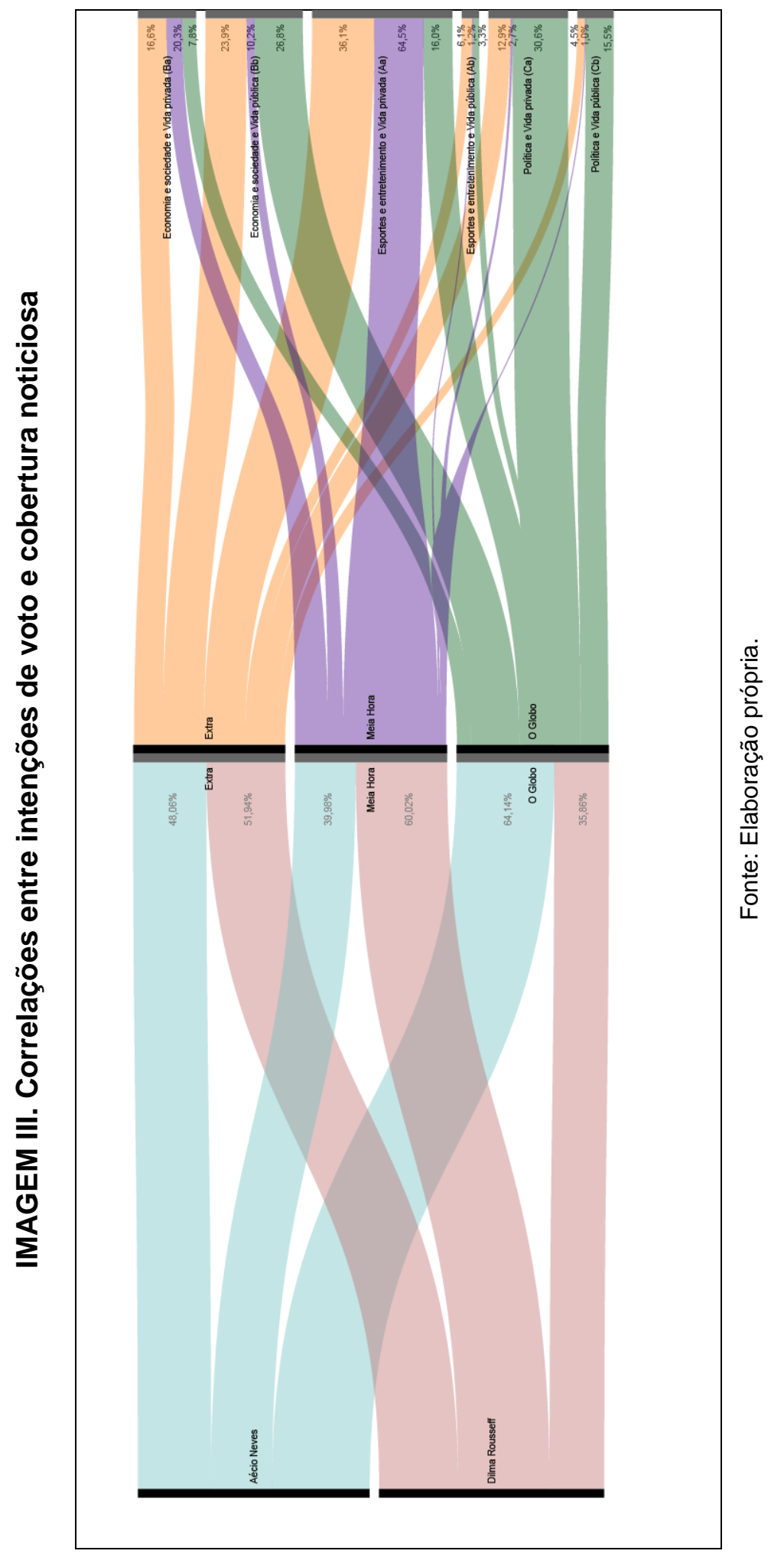


IMAGEM IV. Esquemas interpretativos de O Globo, Extra e Meia Hora

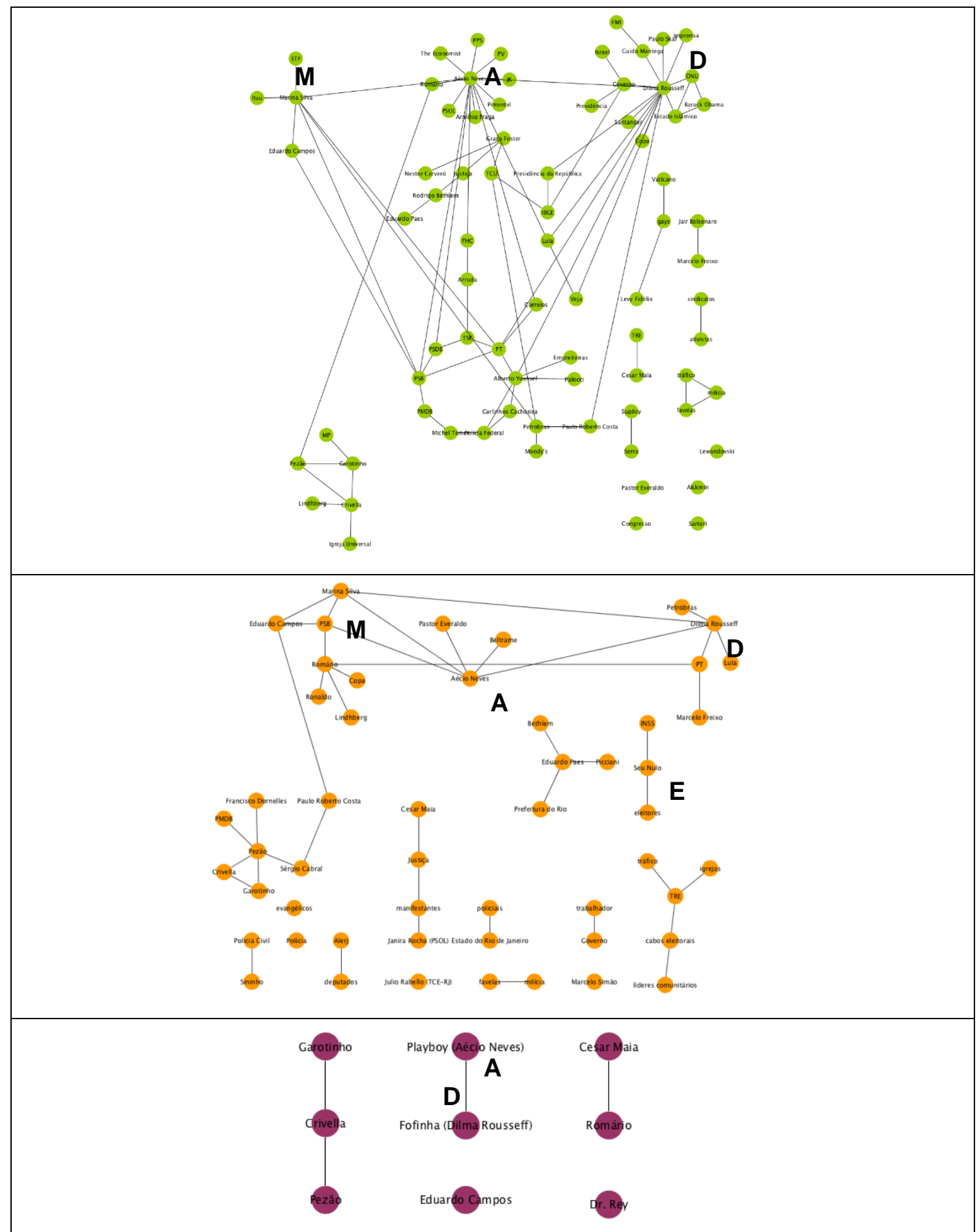

Fonte: Elaboração própria. 
Em O Globo, ainda, os clusters referentes aos candidatos Marina, Aécio e Dilma (marcados com as iniciais) aparece com intensa relação com a cobertura sobre escândalos (o círculo ao centro) e de forma relativamente descolada da cobertura sobre as eleições no estado (cluster à esquerda inferior). No Extra, a cobertura sobre os escândalos está diluída nos clusters dos candidatos, e ganha proeminência o material noticioso que versa sobre segurança pública e questões envolvendo o Governo do Estado e a Prefeitura. No caso de Meia Hora, é curioso notar que os dois candidatos que vão ao segundo turno são os únicos que aparecem, e, assim mesmo, através de personagens caricaturais (a "Fofinha" e o "Playboy"). Marina Silva não recebe menções nas capas, apenas Eduardo Campos, no dia após a sua morte. Em suma, a polarização, no tabloide, é um fato dado, materializado pela referência a uma eleição disputada "pau a pau", uma metáfora que conserva a ambiguidade do tratamento conferido à disputa acirrada e à troca de agressões entre os candidatos. Os apelidos "Playboy" e "Fofinha" também investem em enquadramentos discursivos próprios, caracterizando Aécio como uma figura arrogante, enquanto Dilma é digna de simpatia. No Extra, um quarto cluster aparece no esquema (E), relacionado ao eleitor. O jornal produz uma série de reportagens para orientar o eleitor no momento do voto e constrói a figura do "Seu Nulo", um personagem representado em matérias de enquetes populares (povo-fala) com eleitores indecisos ${ }^{11}$.

Com relação aos enquadramentos substantivos, observamos que, de fato, o Extra e Meia Hora conferem importância destacada ao enquadramento que evidencia o desinteresse por política e chama atenção para o poder do eleitor de mudar o cenário. Já O Globo investe peso considerável de sua cobertura aos escândalos políticos, seguido pela troca de acusações entre os candidatos e entre eleitores nas mídias sociais.

\footnotetext{
11 Para mais sobre a construção e o emprego estratégico de personagens por jornais populares, cf. Nunes (2015).
} 
Tabela IV. Enquadramentos substantivos

\begin{tabular}{|l|l|l|l|}
\hline & $\mathrm{O}$ Globo (N=352) & Extra (N=132) & Meia Hora (N=15) \\
\hline $\begin{array}{l}\text { Sobe e desce } \\
\text { eleitoral / Disputa } \\
\text { acirrada }\end{array}$ & $18,5 \%$ & $23,5 \%$ & $33,3 \%$ \\
\hline Comoção & $4,0 \%$ & $2,3 \%$ & $6,7 \%$ \\
\hline $\begin{array}{l}\text { Escândalos e } \\
\text { corrupção no } \\
\text { centro do poder }\end{array}$ & $21,9 \%$ & $14,4 \%$ & $0,0 \%$ \\
\hline $\begin{array}{l}\text { (Des)Interesse } \\
\text { pela política e o } \\
\text { poder nas mãos do } \\
\text { eleitor }\end{array}$ & $2,3 \%$ & $10,6 \%$ & $26,7 \%$ \\
\hline $\begin{array}{l}\text { Troca de } \\
\text { acusações, } \\
\text { radicalização e } \\
\text { polarização }\end{array}$ & $20,7 \%$ & $11,4 \%$ & $20,0 \%$ \\
\hline $\begin{array}{l}\text { Propostas dos } \\
\text { candidatos }\end{array}$ & $9,4 \%$ & $3,8 \%$ & $0,0 \%$ \\
\hline Corpo a corpo & $3,1 \%$ & $4,5 \%$ & $0,0 \%$ \\
\hline Outros & $20,2 \%$ & $13,3 \%$ \\
\hline
\end{tabular}

Foi realizado ainda um levantamento com base em enquadramentos genéricos, seguindo a proposta de lyengar (1994). Classificou-se os materiais entre enquadramentos temáticos e episódicos (tabela V). Neste caso, apesar de o predomínio de conteúdos episódicos ser amplamente evidente em todos os veículos, Meia Hora foi o que apresentou maior equilíbrio, a despeito da cobertura notadamente menor sobre política.

Tabela V. Enquadramentos procedimentais

\begin{tabular}{|l|l|l|l|}
\hline & $\mathrm{O}$ Globo $(\mathrm{N}=352)$ & Extra $(\mathrm{N}=132)$ & Meia Hora $(\mathrm{N}=15)$ \\
\hline $\begin{array}{l}\text { Enquadramento } \\
\text { temático }\end{array}$ & $8,8 \%$ & $5,3 \%$ & $26,7 \%$ \\
\hline $\begin{array}{l}\text { Enquadramento } \\
\text { episódico }\end{array}$ & $91,2 \%$ & $94,7 \%$ & $73,3 \%$ \\
\hline
\end{tabular}

Fonte: Elaboração própria.

Há também uma diferença qualitativa marcante sobre os conteúdos indicados com enquadramento temático em cada um dos jornais. Em $O$ Globo, as matérias apresentam ao leitor um resumo rápido das eleições. Nas edições dos dias de votação, o jornal trazia um apanhado de reportagens com os respectivos chapéus: "a tragédia", "o escândalo", "o sobe e desce", "as 


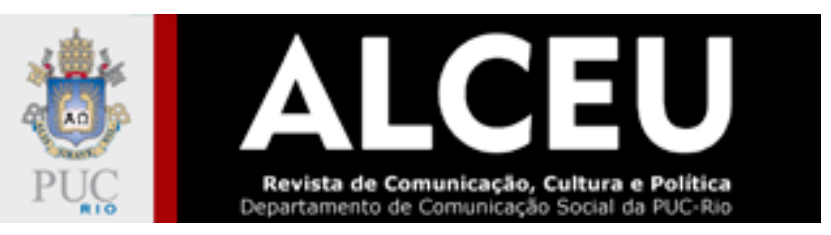

agressões" e "as polêmicas" (5/10); "sobe e desce", "apoios", “agressões", "Petrobras" e "radicalização" (26/10). Em Meia Hora e no Extra, os conteúdos valorizam o caráter de serviço dos jornais, apresentando aos leitores listas com os nomes e números dos candidatos e o passo a passo de como votar na urna eletrônica.

Em suma, embora a presença da cobertura política no quality paper seja decididamente maior, ao se aproximarem mais do leitor, os jornais populares, ao mesmo tempo, favorecem a leitura de que o cidadão comum deve se inteirar mais sobre a política para influir na cena de modo mais contundente, e encorajam a compreensão de que a informação política pode ser absorvida a partir de outros modos que não a cobertura estratégica, típica da imprensa tradicional.

\section{Discussão}

Empreendidas as análises, os resultados demonstram que, enviesada ou não, a cobertura eleitoral na imprensa escrita, tomando-se por base os jornais fluminenses, é superficial e estratégica (Q1). As matérias com chamadas de capa tomam como premissa o interesse do público pela disputa eleitoral, seguindo-se o clássico enquadramento de "corrida de cavalos" (PORTO, 2002) - ou nas palavras dos próprios editores o "sobe e desce eleitoral" (O Globo), a "caixinha de surpresas" (Extra), ou ainda a "disputa pau a pau" (Meia Hora).

As soluções para o duplo problema apresentado pelas Eleições 2014 em todos os três jornais - uma disputa eleitoral polarizada em meio a um anseio generalizado por mudanças na política por parte do eleitorado - varia de acordo com a audiência presumida por cada título. Em $O$ Globo, a solução é reunificar o país, uma atitude que deve partir do grupo eleito. Extra, por sua vez, coloca esta solução nas mãos do eleitor, sugerindo que ele deva se inteirar mais sobre a política antes do voto, e, depois das eleições, deixar de lado as rivalidades. Meia Hora acompanha este raciocínio, indicando que, se o objetivo dos atores em disputa é vencer o pleito, o eleitor deve buscar se informar e manter o bom humor.

De modo geral, com relação à intensidade da cobertura, não houve surpresas, considerandose as diferenças entre quality paper, jornal popular e ultrapopular. Essa diferença, contudo, especialmente no caso dos jornais populares, parece indicar uma contradição em relação aos pressupostos clássicos da teoria dos efeitos, vez que, se o leitor de Meia Hora e do Extra apresentou tendência favorável a votar em Dilma Rousseff, isso não se deve a uma farta cobertura 
noticiosa em favor da candidata, e nem mesmo à intensidade da cobertura sobre a corrida eleitoral. Esses leitores-eleitores provavelmente obtêm a informação política por outro meios, quiçá previamente em relação à escolha do jornal que leem. Em conjunto com a variável econômica a que estão sujeitos os veículos populares - isto é, a condição de dependência em relação ao seu desempenho no segmento da venda avulsa em bancas, em detrimento do apoio estável proporcionado pela base de assinantes -, esse fator poderia explicar, por exemplo, 0 estranhamento diante do fato de que, apesar de editados pelo mesmo conglomerado midiático, 0 Extra e $O$ Globo possuem leitores com tendências políticas tão divergentes, o que repercute na própria linha editorial de cada veículo (Q2).

Esses resultados não só apresentam em maior grau de detalhamento a paisagem políticoeconômica da mídia impressa fluminense no cenário contemporâneo, como nos permitem testar de modo empírico o modelo construído por Sparks (2000) para os estudos sobre a tabloidização norteamericana e europeia. Aplicando este modelo à realidade brasileira, podemos problematizá-lo, buscando alternativas que melhor esclareçam as peculiaridades do contexto nacional.

Em ocasiões anteriores, por exemplo, discutimos (LATTMAN-WELTMAN \& CHAGAS, 2017) como a estratégia de conglomerados midiáticos do jornalismo impresso, como o Infoglobo, de compor uma carteira de produtos destinados a perfis de audiências complementares sócioeconomicamente, tem poupado os jornais de prestígio editados no país, na medida em que a operação de venda casada de publicidade a anunciantes, a venda avulsa de exemplares em bancas de jornais, e a atuação conjunta de profissionais em redações que são unificadas em função da crise no mercado de imprensa permitem equilibrar os custos de produção. Quanto à tabloidização especificamente, nos parece que essa solução de curto prazo tem também garantido que o jornalismo dito de prestígio se mantenha relativamente ilibado, ainda que, como os resultados da presente investigação demonstraram, haja uma crescente evidência de que enquadramentos de caráter mais pessoal e episódico tendam a reduzir a política a uma instância mais comezinha, particularizada e cotidiana. Esses indícios favorecem uma leitura de que a tabloidização é parte das estratégias do jornalismo de qualidade, ainda que o cenário brasileiro não configure essas estratégias como uma resposta à competição com a imprensa ultrapopular, já que a propriedade cruzada dos veículos inibe a dinâmica concorrencial.

Assim, na atual etapa desta pesquisa, temos a concluir que (1) o circuito através do qual o cidadão comum obtém acesso à informação política contemporaneamente é complexo e nuançado; 
(2) não há elementos suficientes para afirmar categoricamente qualquer papel determinante ocupado pela imprensa sobre o resultado eleitoral; ao contrário, o que os dados parecem nos indicar é uma perda de capital político desta mesma imprensa, especialmente a imprensa escrita tradicional, leia-se os quality papers, ante o debate público e a constituição da opinião pública; (3) o processo de profissionalização das empresas jornalísticas tem caminhado pari passu com a desconstrução de uma visão ao mesmo tempo monolítica e hipodérmica dos meios de comunicação, legada particularmente pela reconfiguração recente da economia política da imprensa; e, finalmente, (4) a tabloidização no contexto brasileiro, conquanto guarde similaridades com o relatado pela literatura internacional, apresenta uma série de idiossincrasias, para as quais é necessário empreender observação atenta.

\section{Referências}

BIRD, S. Elizabeth. Audience demands in a murderous market: tabloidization in U.S. television news. In: SPARKS, C. \& TULLOCH, J. Tabloid tales. Nova lorque: Rowman \& Littlefield, 2000.

. Tabloidization: what is it, and does it really matter? In: ZELIZER, Barbie. The Changing faces of journalism: tabloidization, technology and truthiness. New York: Routledge, 2010.

CAPPELLA, Joseph; JAMIESON, Kathleen. Spiral of cynicism. Nova lorque: OUP, 1997.

CHAGAS, Viktor. Papel de embrulhar peixe: uma análise sobre o modelo econômico de distribuição dos jornais e seus prognósticos. Contemporânea, v. 12, n. 1, 2014.

- Economia política do jornalismo popular em perspectiva comparada: uma análise sobre a tabloidização no Brasil, na Índia e na África do Sul. Brazilian Journalism Research, v. 12, n. 1, 2016.

ENTMAN, Robert. Framing: toward clarification of a fractured paradigma. Journal of Communication, v. 43, n. 4, 1993.

. Projections of power. Chicago: UCP, 2004.

ESSER, Frank. 'Tabloidization' of news: a comparative analysis of Anglo-American and German press journalism. European Journal of Communication, v. 14, n. 3, 1999.

FISKE, John. Popularity and the politics of information. In: SPARKS, Colin; DAHLGREN, Peter. Journalism and popular culture. Londres: SAGE, 1992.

. Understanding popular culture. Londres e Nova lorque: Routledge, 2010[1989].

GANS, Herbert. Can popularization help the news media? In: ZELIZER, Barbie. The Changing faces of journalism: tabloidization, technology and truthiness. Nova lorque: Routledge, 2010. 


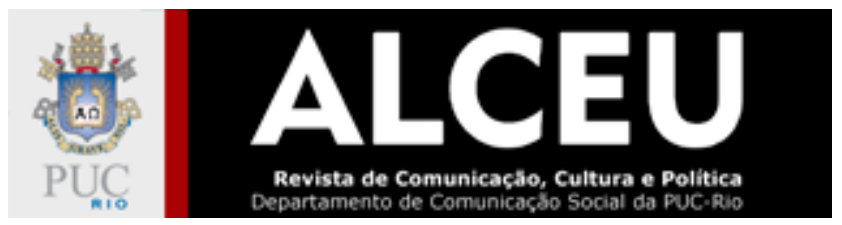

GLYNN, Kevin. Tabloid culture. Durham: DUP, 2000.

IYENGAR, Shanto. Is anyone responsible? How television frames political issues. Chicago: UCP, 1994.

KLEIN, Ulrike. Tabloidized political coverage in the German Bild-Zeitung. In: SPARKS, Colin; TULLOCH, John. Tabloid tales. Lanham: Rowman \& Littlefield Publishers, 2000.

LATTMAN-WELTMAN, Fernando. "Institucionalização midiática e 'representação' política: a construção do cidadão-consumidor nos telejornais". Estudos Históricos, n. 37, 2006.

; CHAGAS, Viktor. Insegurança, (re)partidarização e 'fogo amigo': a economia política dos meios na Era Lula. Eptic, v. 19, n. 2, 2017.

MATTHES, Joerg. What's in a frame? A content analysis of media framing studies in the world's leading communication journals, 1990-2005. Journalism \& Mass Communication Quarterly, v. 86, n. 2, 2009.

MIGUEL, Luís Felipe. Capital político e carreira eleitoral: algumas variáveis na eleição para o congresso brasileiro. Rev. Sociol. Políti., n. 20, 2003.

MENDONÇA, Ricardo Fabrino; SIMÕES, Paula Guimarães. Enquadramento: diferentes operacionalizações analíticas de um conceito. RBCS, v. 27, n. 79, 2012.

NUNES, Angelina. O 'boneco cidadão' e o uso do personagem de um jornal popular para a construção da imagem pública do prefeito carioca. In: VI Compolítica, Rio de Janeiro, 2015.

PECK, Janice. Literacy, seriousness, and the Oprah Winfrey Book Club. In: SPARKS, Colin; TULLOCH, John. Tabloid tales. Lanham: Rowman \& Littlefield Publishers, 2000.

PORTO, Mauro. Enquadramentos da mídia e política. In: XXVI Encontro Anual da Anpocs, Caxambu (MG), 2002.

SPARKS, Colin. Introduction: the panic over tabloid news. In: SPARKS, Colin; TULLOCH, John. Tabloid tales. Lanham: Rowman \& Littlefield Publishers, 2000.

SEYMOUR-URE, Colin. Grapevine politics: political rumours. In: SEYMOUR-URE, Colin. Prime Ministers and the media. Victoria: Blackwell, 2003.

TOUSSAINT, Nadine. A economia da informação. Rio de Janeiro: Zahar, 1979.

Viktor Chagas

Professor da Universidade Federal Fluminense Doutor em História, Política e Bens Culturais (Cpdoc-FGV) ORCID: https://orcid.org/0000-0002-1806-6062 E-mail:viktor@midia.uff.br

Recebido em: 21 de novembro de 2018.

Aprovado em: 15 de agosto de 2019. 


\section{Resumo}

O objetivo deste artigo é relacionar as alterações na paisagem econômica do jornalismo ao processo político. Faremos isto através de dois momentos distintos: em primeiro lugar, estabelecendo relações entre a preferências políticas dos leitores de jornais no Rio de Janeiro e seus hábitos de leitura; depois, avaliando a cobertura política dos jornais através de análise de enquadramentos. Utilizando, como ponto de partida o modelo de análise de Sparks (2000) sobre a tabloidização, buscamos desenvolver uma matriz que avalia a cobertura noticiosa de três jornais fluminenses, a saber: $O$ Globo, Extra, e Meia Hora. Foram analisadas mais de duas mil manchetes e chamadas de primeira página destes jornais, no período entre julho e outubro de 2014, correspondente ao período de propaganda eleitoral, conforme definido pelo TSE. O passo seguinte foi relacionar de volta estas categorias com o perfil dos leitores dos jornais analisados e suas preferências políticas.

Palavras-chave: jornalismo político; eleições 2014; tabloidização.

\section{Abstract}

This article aims to relate the changes in the economic landscape of journalism to the political process itself. We will do this through two distinct moments: first, by establishing relations between the political preferences of newspaper readers in Rio de Janeiro and their reading habits; then evaluating the political coverage of newspapers through a frame analysis. Using Sparks' (2000) model of tabloidization as a starting point, we sought to develop a matrix that evaluates the news coverage of three newspapers from Rio de Janeiro: O Globo, Extra, and Meia Hora. More than two thousand headlines and first page summary texts from these newspapers were analyzed in the period between July and October 2014, corresponding to the period of electoral propaganda, as defined by the Superior Electoral Court. The next step was to relate these categories back to the readers' profile of the newspapers analyzed and their political preferences.

Keywords: political journalism; 2014 elections; tabloidization.

\section{Resumen}

El propósito de este artículo es relacionar los cambios en el panorama económico del periodismo con el proceso político. Lo haremos a través de dos momentos distintos: primero, estableciendo relaciones entre las preferencias políticas de los lectores de periódicos en Río de Janeiro y sus hábitos de lectura; luego, evaluar la cobertura política de los periódicos a través del análisis de encuadre. Utilizando, como punto de partida, el modelo de análisis de Sparks (2000) sobre tabloidización, buscamos desarrollar una matriz que evalúe la cobertura de noticias de tres periódicos en Río de Janeiro, a saber: O Globo, Extra y Meia Hora. Se analizaron más de 2.000 titulares y llamadas de primera plana de estos periódicos entre julio y octubre de 2014, correspondientes al período de propaganda electoral, según lo definido por el TSE. El siguiente paso fue relacionar estas categorías con el perfil de los lectores de los periódicos analizados y sus preferencias políticas.

Palabras clave: periodismo político; elecciones 2014; tabloidización. 